\title{
La república parlamentaria de Chile: perspectivas historiográficas
}

\author{
Fernanda Álvarez Hernández $\left(^{*}\right)^{1}$
}

\section{Vacíos y carencias historiográficas}

La "república parlamentaria" hace alusión a un período atípico en el desarrollo político chileno, en particular por la reducción de autoridad que experimentó la figura presidencial -antaño el gran elector-, potestad que fue transferida al Congreso, en circunstancias que nunca ha existido una forma de gobierno parlamentaria en $\mathrm{Chile}^{2}$. Si se acepta la periodización convencional, se está ante una etapa de corta duración que se prolongó alrededor de 34 años en un espacio de dos centurias. No obstante a su brevedad, posee una gran significación como toda fase o época histórica, en el considerando de que precisamente en esos años la oligarquía, que se formó en la medianía del siglo XIX, desplegó su poder, dando origen a un sistema político y a una forma de hacer política oligárquica. Es el período en el cual se experimentó la emergencia de los nuevos sectores sociales, el proletariado y los sectores medios, que son el fruto del proceso de modernización. Si bien estos dos aspectos mencionados son expresiones de cambio, la continuidad radicó en el campo, espacio que permaneció prácticamente inalterado, sobre todo en cuanto a tenencia de la tierra y régimen laboral.

Actualmente, no existen estudios que integren tanto la variable política con las demográficas, económicas y sociales en el sentido amplio del término. Sólo se encuentran análisis parciales sobre las variables mencionadas de manera aislada, en particular, la dimensión política del parlamentarismo y estudios sobre la conflictividad laboral y social obrera. Los derroteros que han seguido la mayoría de las investigaciones no dan cuenta de una visión integradora que permita transitar desde una historia social a una historia de la sociedad, como propuso Eric Hobsbawm hace ya cuatro décadas ${ }^{3}$. De modo que el panorama historiográfico no se presenta muy auspicioso.

\footnotetext{
(*) Profesora de Estado en Historia y Geografía. Licenciada en Educación. Egresada de la Universidad de La Serena. E-mail: Correo electrónico: fernanda.uls@gmail.com

${ }^{1}$ Estudiante del Programa de Magíster en Historia de la Universidad de Chile. Becaria CONICYT.

2 Burgos, J. y Walker, I., "Hacia el parlamentarismo", en Expansiva, Serie en Foco, n4, 2003, pp. 1 - 10. El sistema político implantado en Chile a partir de 1891 se ha llegado a tildar de seudo, cuasi, semi parlamentario. En otras palabras, un parlamentarismo a la chilena, criollo, bastardeado, alejado de la matriz clásica.

${ }^{3}$ Hobsbawm, E., "De la Historia Social a la Historia de la Sociedad", en Sobre la Historia, Crítica, $3^{\mathrm{a}}$ edición, Barcelona, 2008 , pp. $84-104$.
} 
Los estudios referidos a lo que comúnmente se ha denominado "República Parlamentaria" han sido relativamente escasos en los últimos treinta años. Tanto es así que Harold Blakemore, historiador inglés, especialista en historia política de Chile, aseveró en el año 1983 que hasta la fecha "no se había realizado ninguna investigación sistemática acerca del período parlamentario" ${ }^{\prime 4}$, exceptuando, por cierto, la obra reivindicadora de Julio Heise ${ }^{5}$. Esta situación sólo ha cambiado marginalmente con algunos estudios desarrollados por extranjeros, como las obras de Simon Collier, William Sater, Brian Loveman y el mismo Blakemore. Para el caso chileno, los pocos que han acometido esta tarea, aunque no en profundidad, son Gonzalo Vial, Gabriel Salazar, Julio Pinto y Juan Carlos Yáñez.

En su estudio de principios de la década de 1980, Karen Remmer reparó en el hecho de las exiguas investigaciones en torno al parlamentarismo chileno ${ }^{6}$. A treinta años de esta afirmación sería conveniente preguntarse ¿qué explica la escasez de bibliografía existente y el estado de aridez y estancamiento de los estudios referidos al parlamentarismo? ¿Por qué la renovación de la historia política -por ejemplo- no ha incursionado en este período? Probablemente, esto sea atribuible a que "la mayoría de los historiadores acordaron condenarla como una época estéril en el desarrollo chileno"7 , tal como lo planteó Blakemore. Siendo así ¿qué sentido tenía estudiar una etapa poco fecunda?

Contrario sensu a lo manifestado por René Millar de que el "parlamentarismo es uno de esos escasos temas en que las interpretaciones de la historiografía resultan tan coincidentes" ${ }^{\prime \prime}$, una revisión más exhaustiva lleva a plantear la existencia de un espectro de mayor diversidad en torno al tema.

\section{Trayectorias historiográficas}

Probablemente, el primer análisis del que se tiene registro es el del norteamericano Paul Reinsch, quien en 1909 creyó encontrar un antecedente del parlamentarismo chileno en la Inglaterra aristocrática del siglo XVIII ${ }^{9}$. Resulta interesante que hace ya más de un siglo el sistema político chileno captara la atención de uno de los fundadores de la Ciencia Política estadounidense en el contexto de la fuerte presencia del "progresismo" en el medio académico de aquel país. ¿Cómo se entiende esta paradoja de acuerdo con la cual la historiografía nacional no ha abordado este tema que cruza el período de la más aguda y prolongada crisis social -cuando no integral-10 del país?

\footnotetext{
${ }^{4}$ Blakemore, H., "El período parlamentario en la Historia chilena. Algunos enfoques y reflexiones", en Ortega, L. (ed.), Dos estudios sobre salitre y política en Chile. 1870 - 1895, Ed. Departamento de Historia Universidad de Santiago de Chile, Santiago, 1991, p. 31.

${ }^{5}$ Heise, J., Historia de Chile. El período parlamentario. 1861 - 1925, Editorial Andrés Bello, Santiago, 1973, Tomo I, pp. 269 - 355.

6 Blakemore, H., "El período parlamentario", p. 31.

${ }^{7}$ Ibíd.

${ }^{8}$ Millar, R., "El parlamentarismo chileno y su crisis, 1891 - 1924", en Genaro Arriagada, et. al., Cambio de régimen político, Ediciones Universidad Católica de Chile, Santiago, 1992, p. 250.

${ }^{9}$ Reinsch, P., "Parlamentary Government in Chile", en The American Political Science Review, vol. 3, n 4, 1909, p. 508.

${ }^{10}$ Concepto acuñado por Ahumada, J., “La crisis integral de Chile”, en En vez de la miseria, Editorial del Pacífico, Santiago, 1958, cap. I, pp. 14 - 52.
} 
Reinsch concluyó su estudio afirmando que producto de las disputas de carácter personal que se generaban al interior del Congreso y de la insistencia de demandas locales, "el parlamento [era] estéril en lo que dice relación a su actividad legislativa real [En pocas palabras] el parlamento chileno se [dedicó] a administrar y en el intertanto se [tornó] ajeno al arte de gobernar"11. Uno de los aportes de este autor fue buscar antecedentes de clase en los parlamentarios, llegando a plantear que las características del sistema político chileno tenían una estrecha relación con la composición social de ese cuerpo, los cuales mayoritariamente eran grandes propietarios de la tierra, aunque no necesariamente de linaje aristocrático ${ }^{12}$. Esta propuesta apunta a un complejo mecanismo de cooptación de la oligarquía a través del cual, desde mediados del siglo XIX, este grupo consolidó su hegemonía y estableció, a partir de 1891, un sistema político afín a sus intereses: el parlamentarismo ${ }^{13}$.

Tributarios de algunos planteamientos de Reinsch -el análisis de clase y la esterilidad política- fueron los historiadores marxistas que comenzaron su producción en la década de 1950. Los análisis de Fernando Ortiz Letelier, discípulo de Hernán Ramírez Necochea, derivaron en la visión de un régimen viciado y decadente caracterizado por los sucesivos cambios ministeriales, obstrucciones al despacho de leyes formuladas por el Ejecutivo, interpelaciones, censura a los ministros e interminables discusiones de los congresales, tras las cuales habrían actuado "definidos intereses de clase"14. Con un enfoque más matizado, Julio César Jobet manifestó, de manera explícita, la esterilidad de la administración pública producto, precisamente, de las características del sistema político ${ }^{15}$, constituyendo la primera interpretación proveniente de esta visión. Los planteamientos de estos autores son, en líneas gruesas, representativos de la corriente marxista, los cuales imputaron a la oligarquía la creación y el manejo del régimen parlamentario e incluso la posesión de rasgos feudales, debido a la adopción acrítica de las categorías de análisis generadas en la Academia de Ciencias de la U.R.S.S. durante el período estalinista.

Una mirada igualmente crítica, aunque en el extremo opuesto del espectro, se deriva de las obras inscritas en la vertiente conservadora nacionalista de la tercera década del siglo XX. Alberto Edwards, un hombre multifacético que escribió desde novelas policiales hasta radioteatro y que curiosamente ha sido muy influyente en la historiografía, aplicó el concepto de "paz veneciana" para definir el tipo de política que se desarrolló durante el período ${ }^{16}$. Este constructo conceptual hacía alusión a la política de salón "desarrollada entre magnates del mismo rango, no divididos ni por las ideas ni por los intereses. Amigos o parientes que distraían los ocios de la opulencia en el juego de los partidos y de las crisis sociales"17. Para este autor la esencia del parlamentarismo era la práctica institucionalizada de los cambios en

\footnotetext{
${ }^{11}$ Reinsch, "Parliamentary Government", pp. 535 - 536.

${ }^{12} \mathrm{El}$ autor hace referencia a dueños de grandes haciendas, empresas industriales y mineras. Estos apellidos se encontraban integrando el Congreso, tales como: Concha, Subercaseaux, Tocornal, Errázuriz, Vergara, Zañartu, Irarrázaval, Edwards, Balmaceda, Walker, entre otros. Ibíd, pp. 508 - 509.

${ }^{13}$ Carmagnani, M., Estado y Sociedad en América Latina, Ed. Crítica, Barcelona, 1884. Para un sentido más amplio sobre la formación de las elites, ver Burke, P., Venecia y Amsterdam, Estudio sobre las elites del siglo XVII, Crítica, Barcelona, 1996.

${ }^{14}$ Ortiz Letelier, F., El movimiento obrero en Chile (1891 - 1919). Antecedentes, Ediciones LOM, Santiago, 1985 , p. 193.

${ }^{15}$ Jobet, J., Ensayo histórico del desarrollo económico-social de Chile, Editorial Universitaria, Santiago, 1955, p.114.

${ }^{16}$ Un análisis sobre las características de este tipo de política en Burke, Venecia y Amsterdam.

${ }^{17}$ Edwards, A., La fronda aristocrática, Editorial Universitaria, 8ª Edición, Santiago, 1982, p. 192.
} 
los gabinetes, rotulándolos como meros "fantasmas de teatro"18. Debido al letargo político que habría caracterizado a esta época, la que se enmarca dentro de la tercera fase de la "República en forma" (1890-1920) ${ }^{19}$, es que no se estaría en condiciones de escribir "alta historia de esos años" 20 .

Gonzalo Vial, décadas más tarde, siguió de cerca la interpretación de Edwards, añadiendo que los máximos responsables de la ineficiencia del parlamentarismo fueron los partidos políticos, al carecer de principios doctrinarios sólidos, de una organización eficiente y de disciplina. Sistema de partidos políticos que tienen su origen en el conjunto de reformas de la década de 1870, tal como plantea Samuel Valenzuela ${ }^{21}$. Los elementos de corrupción e ineficiencia del parlamentarismo, presentes tanto en las visiones marxistas y conservadoras, estimularon una enérgica condena. Esta línea de análisis está relacionada de manera directa con el proceso de aguda decadencia que, a juicio de Vial, afectó a la clase dirigente de la época. Uno de los signos del declive y ceguera que afectaba a la clase política se hallaría en los eventos de diciembre de 1907 donde la "lacra" parlamentaria teniendo los hechos ante sus ojos fue incapaz de solucionar los problemas sociales generándose, de tal forma, el quiebre del tercer consenso ${ }^{22}$.

Las visiones de Edwards y Vial están condicionadas, en gran medida, por reconocer en la obra de Portales los máximos ideales y valores que deberían caracterizar a un gobierno eficaz y, por consiguiente, ver en el parlamentarismo la decadencia de la oligarquía liberal. Sus coincidencias van más allá de una mera postura historiográfica, pues ambos comparten la experiencia de haber sido Ministros de Educación en regímenes dictatoriales: uno, al final de la dictadura de Ibáñez en 1931; el otro, en el momento de consolidación de la de Augusto Pinochet en 1979 - 1980. Símbolos, ambos, del rebrote autoritario en la historia del país durante el siglo XX.

Mario Góngora, otro de los autores que adhirió a esa visión conservadora, si bien critica algunos de los planteamientos de la obra más importante de Edwards, coincide con el enfoque que posee aquel respecto a la etapa parlamentaria. En sus estudios más tardíos, Góngora exhibió dos grandes coincidencias con Edwards. En primer lugar, la denominación de "política fantasmagórica" a las prácticas que habrían tenido lugar en el Congreso. En segundo término, así como Edwards "creyó ver en la dictadura del general Ibáñez la restauración histórica de la estabilidad normal del Estado, [Góngora creyó] lo mismo, al comienzo, en el régimen del General Pinochet" ${ }^{\prime 23}$. El sentimiento de crisis y de decadencia que visualizó este autor se asemeja no sólo a los planteamientos de Edwards sino a los análisis elaborados por Francisco Antonio Encina. Este último, a pesar de compartir con Edwards una admiración por el régimen portaliano, la

\footnotetext{
${ }^{18} \mathrm{Ibid}$, p. 174.

${ }^{19}$ Para Edwards la historia de la "República en forma" puede dividirse en tres períodos: 1) 1830 a 1860 o etapa en donde se gobernó sobre los partidos (aunque puede decirse que, en estricto rigor los partidos no existían); 2) 1860-1890 o etapa donde se gobernó "con los partidos". Aquí se daría una especie de equilibrio no siempre estable entre la autoridad presidencial y los círculos en que se apoya; y 3) 1890 - 1920 o etapa en donde la autoridad presidencial "desaparece". Ibíd, pp. 130 - 134. ${ }^{20} \mathrm{Ibid}, \mathrm{p} .156$.

${ }^{21}$ Valenzuela, S., Democratización vía reforma. La expansión del sufragio en Chile, Ediciones del Ides, Buenos Aires, 1985, pp. 140 - 143.

${ }^{22}$ Vial, G., Historia de Chile, 1891 - 1973, Editorial Santillana del Pacífico, Santiago, 1981, Tomo II, Vol. I, p. 850.

${ }^{23}$ Carta de Mario Góngora a revista Nueva Historia, Londres, no 8 (1983), p. 286.
} 
visión decadentista de la sociedad y la poca adhesión a las prácticas de la democracia liberal, se distanció con moderación de la generalizada visión negativa del período parlamentario ${ }^{24}$, probablemente por su calidad de protagonista en el acontecer político de esos años, donde ocupaba un escaño en el Congreso. En las páginas finales del tomo XX de su Historia de Chile, afirmó de manera sucinta que la visión que se tenía de esa etapa era exageradamente negativa, en razón de que los propios contemporáneos, al ver frustradas sus ilusiones, se encargaron de desprestigiarlo ${ }^{25}$. Si bien Encina no emprendió un estudio sistemático sobre esta etapa, Leopoldo Castedo, encargado de condensar su extensa obra en los conocidos tres tomos del Resumen de la Historia de Chile, redactó un IV tomo en el que incluyó la época parlamentaria, respetando la visión de Encina sobre el período ${ }^{26}$.

En las antípodas de estos enfoques cargados de crítica y en abierta discrepancia respecto de los juicios peyorativos, se encuentran los planteamientos del historiador y abogado Julio Heise. El objetivo que persiguió al analizar el parlamentarismo fue declaradamente revisionista, lo que explica el énfasis puesto en aspectos exclusivamente positivos. Entre sus aportes cabe destacar la alteración de la datación tradicional del parlamentarismo en Chile, estableciendo los inicios de este sistema de gobierno en la administración de José Joaquín Pérez en 1861. En segundo lugar, el significado histórico que habría tenido la etapa parlamentaria como escuela cívica del pueblo chileno, traducido en el acato a la legalidad y el mantenimiento del orden constitucional. Por último, el desarrollo incipiente de una democracia social contemporánea, basada en el respeto de las libertades públicas. La visión de Heise, de gran interés por destacar aspectos no estudiados o, simplemente, ignorados por la historiografía, brinda una mirada distorsionada del asunto, lo que la ha expuesto a fuertes críticas. Bajo esa perspectiva, es válido el cuestionamiento de Harold Blakemore, en el considerando de que los cuestionamientos hechos al sistema político y deconstruidos por este autor no siempre se basaron en material empírico que lo demostrara ${ }^{27}$. Sin embargo, por otro lado, el mérito de la obra de Heise, en palabras de Feliú Cruz, es el de constituir el primer estudio sistematizado del período parlamentario.

No distante de la visión de Heise, y con un enfoque que denota cierta sobrevaloración de la elite, Juan Carlos Yáñez postula que no habrían existido críticas de carácter global al régimen por parte de los contemporáneos, a raíz de que "casi todos consideraron que el sistema era el que mejor garantizaba la participación de todos los sectores y la estabilidad necesaria para promover los cambios" ${ }^{28}$. En consecuencia, las críticas apuntaban a imponer un régimen parlamentario propiamente tal. De esa forma, el autor plantea una pregunta fundamental ¿si el parlamentarismo se tornó

\footnotetext{
${ }^{24}$ Encina planteó que la obra de Edwards, La Fronda Aristocrática, posee numerosas contradicciones que han impuesto la creencia de que el sistema político implantado en 1891 engendró una parálisis política completa, que se prolongó hasta 1920. En Encina, F., Historia de Chile desde la Prehistoria hasta 1891, Ed. Nascimento, Santiago, 1954, Tomo XX, p. 343. ${ }^{25}$ Millar, "El parlamentarismo chileno".

${ }^{26}$ Castedo, L., Chile: vida y muerte de la república parlamentaria (de Balmaceda a Alessandri, Editorial Sudamericana, Santiago, 2001). El libro es una versión revisada de una edición que Leopoldo Castedo publicó en 1983.

${ }^{27}$ Blakemore, "El período parlamentario", p. 46.

${ }^{28}$ Yáñez, J., Estado, consenso y crisis social. El espacio público en Chile, 1900 - 1920, Ediciones DIBAM, 2004, Santiago, p. 37.
} 
tan negativo por qué su duración fue tan prolongada? Es sabido que la durabilidad no siempre es garantía de efectividad. Un sistema político con altos grados de eficiencia se mide por su capacidad de dar respuesta a los problemas que impone su sociedad. Un ejemplo de ello, es el caso italiano de la post Segunda Guerra Mundial, donde gobiernos de corta duración, por tres décadas, permitieron el crecimiento económico y un alto grado de modernización, aunque confinados al centro y norte del país. La pregunta entonces debería ser replanteada: ¿cómo logró el sistema político absorber las tensiones sociales que detonaban por aquellos años, propias de una sociedad en transición? Entre otros aspectos, Yáñez aborda el tema del espíritu conciliador del sistema político, en donde las negociaciones y la búsqueda de acuerdos para la formación de mayorías en el Congreso se convirtieron, a la larga, en el sustrato del parlamentarismo ${ }^{29}$. En otras palabras, la continuidad y supervivencia del régimen habría radicado en las prácticas de conciliación al interior de ambas cámaras. Indudablemente, el autor omite el hecho de que se trató de un consenso oligárquico, "desde arriba", en donde el resto de los actores sociales no estaban incluidos.

En términos de consenso, es pertinente citar la obra de Gabriel Salazar quien propone el concepto de "paz oligárquica" para explicar la ausencia de guerras civiles entre las elites y conflictos exteriores, debido a las negociaciones y pactos convenidos en el parlamento, los cuales habrían frenado el eventual quiebre de la unidad interna del Estado ${ }^{30}$. De tal manera que el consenso civil y la desmilitarización actuarían, para Salazar, como indicadores de la modernización del sistema político, el que habría transitado hacia la democracia liberal, tal como lo planteó en 1979 Julio Heise. Democracia liberal de ribetes neo portaleanos "que perpetuaba una dudosa estabilidad institucional"31. En este punto Salazar deja planteada la duda respecto a la estabilidad sin resolver su aseveración. Si se tiene en consideración el escenario político inaugurado por los enfrenamientos de 1891 y culminado "a punta de sables" en 1925, se podría postular -de manera hipotética- que el gobierno de Arturo Alessandri introdujo ciertos elementos de inestabilidad al sistema político, no obstante, continuó su funcionalidad en la medida que las elites y sus partidos pudieron ejercer el poder político y gobernar por un espacio de treinta y tres años.

El proceso netamente político del que trata Salazar no trajo aparejado cambios que se tradujeran en avances en el plano económico y social, pues el "el parlamentarismo chileno no había entrado en escena para resolver esos problemas sino, más específicamente, para asegurar la sobrevida de las élites mercantiles" ${ }^{\prime 32}$. Blakemore en su contribución a la Historia de Cambridge señaló, de manera similar, la incapacidad de la clase dirigente en reconocer que la democracia política sin un grado de democracia social y económica "no [era] más que la forma sin el contenido" ${ }^{33}$.

\footnotetext{
${ }^{29}$ Ibíd, pp. $31-32$

${ }^{30}$ Comparativamente, Salazar hace referencia a la conservación de un consenso, mientras que Vial indica la ruptura de tres de ellos: doctrinario, político y social.

${ }^{31}$ Salazar, G., Violencia política popular en las "Grandes Alamedas", Santiago de Chile, 1947 - 1987, Ediciones SUR, Santiago, 1990, p. 72.

${ }^{32}$ Ibíd., p. 74.

${ }^{33}$ Blakemore, H., "Desde la Guerra del Pacífico hasta 1930", en Bethell, L. (ed.), Chile desde la Independencia, Ediciones Universidad Católica Silva Henríquez, Santiago, 2009, p. 49.
} 
Por otro lado, en dos breves páginas, Julio Pinto señala que en el cambio de siglo la elite dirigente "enfrentó una crisis de legitimidad y predominio político, y por extensión, pareció haber un cambio de la sociedad en su conjunto" ${ }^{\prime 34}$. Pero ¿a qué crisis de legitimidad se refiriere el autor? más bien ¿de dónde provenía esa legitimidad? Ciertamente, afloraba desde la misma elite por medio del control de las fuentes de riqueza, el prestigio y el poder político, como señala Peter Burke ${ }^{35}$. Por lo que es poco plausible pensar en heridas autoinfligidas como lo da a entender el autor al declarar que "esta 'clase' extrapoló la sensación de crisis al conjunto de la sociedad; sintieron que era el país el que se deslizaba hacia el desastre" ${ }^{\prime 36}$. Sin embargo, tanto la emergente clase media y el proletariado ¿cuestionaron las bases del poder oligárquico? Al parecer su crítica iba dirigida a las formas del ejercicio del poder de la elite y no a los soportes de su legitimidad.

\section{Nuevos enfoques y perspectivas de estudio: visiones en el extranjero y aportes de las variables económicas y demográficas}

En más de una oportunidad se ha hecho mención a investigaciones de historiadores extranjeros que se han embarcado en el estudio del pasado chileno. El propósito de elaborar un balance historiográfico exhaustivo obliga a detenerse en algunas consideraciones contempladas en sus obras.

El inglés Simon Collier en unión al norteamericano William Sater, señalaron en el 2004 que la república parlamentaria podía ser entendida como la "última fase del dominio oligárquico" ${ }^{\prime 37}$. En consonancia con los planteamientos de estos autores, Marcello Carmagnani, en sus estudios de historia política y social que caracterizaron su segunda etapa como historiador, analizó la formación de las oligarquías latinoamericanas, indicando que durante los años 1861 - 1871 se asistió a la transición pacífica y controlada por el gobierno central, del estado autocrático al oligárquico, constituyendo el período 1880-1914 la edad de oro de la oligarquía ${ }^{38}$. Carmagnani con un análisis más profundo y audaz, señaló que el proyecto de las elites -que presuponía el establecimiento de un "orden económico, social y político que fuera otro, pero que, al mismo tiempo, no alterase en exceso ningún mecanismo fundamental del ya existente" ${ }^{\prime \prime 3}$ - se convirtió en la gran ilusión de la oligarquía. Si su hipótesis es aplicable a Chile ¿cómo se plasmó? El desarrollo de una política gatopardista puede ser interpretada en el sentido de liberalizar el sistema político, pero sin eliminar los anacronismos de las inequidades urbanas, la estructura de la propiedad agraria, las relaciones de dominación al interior de ella entre hacendados e inquilinos que, dicho sea de paso, constituía el sustrato de la sociedad tradicional.

El tema de las clases medias ha sido escasamente estudiado por los exponentes de la nueva historia social. Uno de los pocos historiadores que incorporó este segmento social a sus reflexiones fue Mario Góngora hace ya tres décadas. En cuanto a los estudios extranjeros, para la etapa parlamentaria, Collier y Sater señalaron que la clase media "distintivamente heterogénea por naturaleza, no se podía realmente movilizar de la

\footnotetext{
${ }^{34}$ Salazar, G. y Pinto, J., Historia contemporánea de Chile, Ediciones LOM, Santiago, 1999, Vol. II, p. 40.

${ }^{35}$ Burke, Venecia y Amsterdam.

${ }^{36}$ Salazar y Pinto, Historia contemporánea, p. 40.

${ }^{37}$ Collier, S. y Sater, W., A History of Chile, 1808 - 2002, Cambridge University Press, 2a Edición, United Kingdom, 2004 , p. 149.

${ }^{38}$ Carmagnani, M., Estado y Sociedad, p. 96.

${ }^{39}$ Ibid, p. 98.
} 
manera como lo hacía el movimiento laboral" ${ }^{\prime 40}$. Una visión más matizada al respecto es la que expone el historiador y cientista político estadounidense Brian Loveman, para quien el sistema parlamentario habría posibilitado un "modesto aumento de la influencia política de la clase media y de los intereses provinciales"41. Contrariando los enfoques de estos autores y de aquellos que han visto al movimiento obrero como protagonista del acontecer histórico, Carmagnani postuló la idea de que la principal amenaza a la hegemonía oligárquica no provenía del proletariado, debido a que este sector "era cuantitativamente escaso, estaba confinado a un espacio geográfico restringido y por consiguiente fácil de controlar" 42 . Bajo este proceder ¿qué sector social o productivo se perfiló como el mayor peligro para la elite parlamentaria? De acuerdo con la hipótesis del autor para los casos latinoamericanos, los principales problemas los plantearon las "capas medias de la población, peligrosas porque de ellas dependía el funcionamiento del comercio y de todo el aparato social" ${ }^{\prime \prime}$. Teniendo en consideración los postulados de Carmagnani ¿se podría interpretar que las condiciones para la formación de un movimiento obrero propiamente tal habrían sido insuficientes e incluso inexistentes? Si se está en desacuerdo con este razonamiento y se fundamenta la efectiva movilización de los trabajadores cabría preguntarse si éstos ¿intentaron plantearse como un real desafío al poder oligárquico con afanes transformadores de la sociedad o, por el contrario, no se propusieron modificar el statu quo, sino que únicamente obtener del sistema político una respuesta a sus reivindicaciones más elementales de "pan, techo y abrigo"?

La mayoría de las investigaciones aquí citadas constituyen estudios dedicados a materias esencialmente políticas y sociales, en donde se hace un tratamiento de este tema bajo su modalidad de sistema político y las consecuencias sociales que éste engendró. El pensar el parlamentarismo no sólo desde el prisma político, sino más bien como período histórico, demandaría un análisis extensivo a otras dimensiones, que incursionara en los planos demográfico y económico, los cuales entregan claves importantes para entender el estallido de la crisis social finisecular.

En Chile, son escasos los historiadores sociales que al analizar las vicisitudes sociales y políticas del período comprendido por el parlamentarismo criollo han analizado los factores demográficos y productivos. Sin embargo, fue precisamente en aquellos años que la sociedad chilena comenzó a sentir de manera creciente el impacto del proceso de transición y modernización económica y social desde formas tradicionales de distribución de la población y de organización de la producción y de la fuerza de trabajo que se inició a mediados del siglo XIX, como lo han sugerido Thomas F. O’Brien y Luis Ortega ${ }^{44}$.

Ya en 1966 Carlos Hurtado publicó un importante estudio en que demostró empíricamente la lenta, pero inexorable transición demográfica que se inició en torno

\footnotetext{
${ }^{40}$ Collier y Sater, A History of Chile, p. 199.

${ }^{41}$ Loveman, B., Chile: The legacy of Hispanic capitalism, Oxford University Press, 3a Edición, New York, 2001 , p.164.

${ }^{42}$ Carmagnani, Estado y Sociedad, p. 127. El autor agrega que "el proletariado pese al tiempo transcurrido y a los progresos realizados, era todavía una capa social poco numerosa, que había conseguido una cierta solidaridad interna, pero que no había encontrado aún el modo de efectuar la conexión entre sus diversos núcleos constitutivos, urbanos y mineros", p. 141. ${ }^{43}$ Ibid, p. 127.

${ }^{44} \mathrm{O}^{\prime}$ Brien, T., The Nitrate Industry and Chile's Crucial, 1870 - 1891, New York University Press, New York, 1982. Ortega,

L., Chile en ruta al capitalismo. Cambio, euforia y depresión, Dibam-LOM, Santiago, 2005, cap. II, III y IV.
} 
a la medianía del siglo XIX ${ }^{45}$. Dicho proceso, escasamente estudiado, implicó una creciente aglomeración de la población que tuvo su origen en una constante migración desde el campo a las ciudades de mayor tamaño del núcleo central y a los distritos mineros del norte grande. A pesar de las cifras calculadas por Hurtado, Armando de Ramón y Patricio Gross demostraron que ni Santiago ni las demás ciudades de mayor tamaño estaban en condiciones de asimilar de manera satisfactoria tal aumento de población, pues ni su infraestructura social, su dotación de servicios, o su stock de viviendas eran suficientes o fueron adaptadas para responder airosamente a las presiones de una creciente demand $\mathrm{a}^{46}$. Se generó, de tal forma, una coyuntura en la que todas esas carencias se constituyeron en fuentes de especulación, de amenazas a la calidad de vida y, finalmente, de crecientes protestas ${ }^{47}$. En efecto, los problemas relacionados con el costo y la calidad de la alimentación y la vivienda, junto con el tema de la extensión de la jornada de trabajo, nutrieron en forma determinante gran parte del contenido de las protestas sociales del período 1900 - 1927, como lo ha destacado Peter De Shazo ${ }^{48}$. Tampoco las respuestas de las ciudades fueron satisfactorias en términos de la creación de empleo, a pesar de que en las principales aglomeraciones se verificó un proceso de industrialización según los datos de Marcello Carmagnani y Henry W. Kirsch ${ }^{49}$.

Desde el punto de vista de los sectores productivos en su totalidad, Carmen Cariola y Osvaldo Sunkel señalaron que la demanda generada por la región salitrera reemplazó a los mercados externos perdidos por la agricultura durante la crisis de la segunda mitad de la década de 1870 y en la práctica ello fue un desincentivo para la innovación y especialización productiva ${ }^{50}$, lo cual redundó en el estancamiento económico y social del campo. Según Arnold Bauer, fue en ese período que la agricultura confirmó sus rasgos tradicionales en cuanto al proceso de producción como a los sistemas laborales, siendo su contribución al desarrollo del mercado interno prácticamente nula ${ }^{51}$.

Si hubo una relación entre la crisis social finisecular y el pobre desempeño de la economía en el período parlamentario, cabe preguntarse ¿qué ocurrió entre 1880 y 1920, etapa en que el país obtuvo ingresos sin precedentes por exportaciones, y que

\footnotetext{
${ }^{45}$ El autor calculó que entre 1865 y 1930 la población total del país aumentó de 1.879.345 habitantes a 4.287.443, al 1,5 por ciento acumulativo anual. Hurtado, C., Concentración de población y desarrollo económico. El caso chileno, Universidad de Chile, Santiago, 1966, cap. II, y III. No obstante, en 1930 un cuarto de la población nacional residía en las cuatro ciudades que ponderaban más de 50.000 habitantes: Santiago, Valparaíso, Concepción y Antofagasta. De Shazo, P., Trabajadores urbanos y sindicatos en Chile: 1902 - 1927, Centro de Investigaciones Barros Arana, Santiago, 2007 , p. 32.

${ }^{46}$ De Ramón, A., Gross, P. y Vial, E., Imagen ambiental de Santiago 1880 - 1930, Ediciones Universidad Católica de Chile, $2^{a}$ Edición, Santiago, 1984. De Ramón, A. y Gross, P. (comp.), "Santiago de Chile: características histórico ambientales, 1891 - 1924", en Nueva Historia, Londres, vol. 4, (1985).

${ }^{47}$ Fue en esas circunstancias que se acuñó la consigna "pan, techo y abrigo".

${ }^{48}$ De Shazo, Trabajadores urbanos, p. 32.

${ }^{49}$ Carmagnani, M. Desarrollo Industrial y Subdesarrollo Económico: el caso chileno, 1860-1920, Dibam, Centro de Investigaciones Barros Arana, Departamento de Ciencias Históricas, Universidad de Chile, Santiago, 1998. Kirsch, H., Industrial Development in a Traditional Society. The Conflict of Entrepreneurship and Modernization in Chile, University of Florida, Gainesville, 1977. Hacia 1895 en el país habían 2.449 fábricas, mientras que en 1925 eran 3.221 , con un total de 83.779 trabajadores que representaban aproximadamente el 10\% de la población económicamente activa del país, datos en De Shazo, Trabajadores urbanos, p. 43.

${ }^{50}$ Cariola, C. y Sunkel, O., Un siglo de historia económica en Chile 1830 - 1930, Editorial Universitaria, Santiago, 1991, segunda parte, pp. 63 - 192.

${ }^{51}$ Bauer, A., La sociedad rural chilena. Desde la conquista española a nuestros días, Andrés Bello, Santiago, 1994 , pp. 257 - 278. Ortega, L. y Araya, P., "Economía política y políticas económicas durante la república salitrera, 1880 - 1914 ", en Contribuciones Científicas y Tecnológicas, Santiago, n¹16, (1997). Cariola y Sunkel, Un siglo de historia económica, pp. 107 - 192.
} 
sólo se igualaron, en términos per cápita, a fines de la década de 1980? En ese período, según los cálculos de Markos J. Mamalakis, el país recibió ingresos por retorno de las exportaciones de una magnitud tal, que se comparan de manera favorable con cualquier ciclo exportador en el período 1820 - $1973^{52}$ ¿Por qué tan sólo dos décadas después de haber conquistado esa riqueza el país estaba sumergido en una crisis social sin precedentes? Según Carlos Hurtado, hay varias respuestas posibles ${ }^{53}$. Una respuesta compleja demandaría examinar el manejo macroeconómico, y ello es importante, pues se vincula a la forma de hacer política del período parlamentario, en particular, la política fiscal catalogada como "relajada" y la política tributaria designada como de "exención", además de los magros resultados obtenidos a lo largo de la etapa. Temática estudiada principalmente por Carlos Hurtado, Markos Mamalakis, René Millar ${ }^{54}$ y Manuel Fernández ${ }^{55}$.

En consecuencia, durante el período parlamentario la oligarquía hizo realidad uno de los pilares de su diseño estratégico, financiar el Estado a través de un fuerte vínculo con la economía internacional que le evitase tener que contribuir a las finanzas públicas, tal como lo planteó Carmagnani ${ }^{56}$. En esa decisión participaron todos los sectores, con algunas voces disidentes que no hacían más que confirmar la regla. Es así como el Estado devino en un dispensador de bienes, servicios, empleos públicos, subsidios y exenciones tributarias que, ciertamente, favorecían a los sectores que lo controlaban. Cabe preguntarse si el haber destinado una parte de esos recursos a mitigar las carencias de los sectores que demandaban mejores condiciones de vida hubiese, en alguna medida, aplacado la crisis social. Probablemente sí, pero ello no era esperable dadas las características y composición del sistema político, pero sobre todo por sus fundamentos doctrinarios.

Si bien las variables demográficas y económicas tratadas por diferentes historiadores no explican a cabalidad los temas sociales característicos del primer cuarto del siglo $X X$, constituyen elementos fundamentales para una integral comprensión de la naturaleza de los problemas sociales del cambio de siglo. Confinar el análisis a elementos exclusivamente políticos o ideológicos es hacer exclusivamente ideología.

\section{Consideraciones finales}

En materia historiográfica, el parlamentarismo adolece de estudios sistemáticos. La mayor parte de la producción ha sido seducida por el análisis de la conflictividad social y laboral, temática que se ha teñido de cierto esencialismo al basarse casi exclusivamente en el movimiento popular y obrero; otros tantos, se han centrado en las dimensiones políticas del período. Son exiguos los estudios que integran en sus análisis las variables económicas y demográficas, las cuales se encuentran trabajadas

\footnotetext{
${ }^{52}$ Mamalakis, M., The Growth and Structure of the Chilean Economy from Independence to Allende, Yale University Press, New Haven, 1976, pp. 15 - 16.

${ }^{53}$ Hurtado, C., De Balmaceda a Pinochet, Logos, Santiago, 1988, cap. II; Ortega y Araya, "Economía política".

${ }^{54}$ Millar, R., Políticas y teorías monetarias en Chile, Universidad Gabriela Mistral, Santiago, 1994, cap. II, pp. 174 - 334.

${ }^{55}$ Fernández, M., "El enclave salitrero y la economía chilena 1880-1914", en Nueva Historia, Londres, n 3, (1891).

${ }^{56}$ Carmagnani, Estado y Sociedad, cap. II. Conviene recordar que el título original de este libro en italiano es La Grande Illusione della Oligarchie Latinoamericana.
} 
de manera aislada. De modo que en la actualidad este período histórico espera aún por ser explorado.

El parlamentarismo fue una etapa inundada de desequilibrios, resultado directo de la transición de la sociedad hacia la modernidad, sociedad que coexistió con la inflexibilidad de un sistema político que no había sido pensado para responder al conjunto de demandas sociales; por el contrario, el parlamento fue creado para resolver los problemas de la elite, negociar acuerdos y administrar directamente el erario nacional -constituido fundamentalmente por las riquezas derivadas del salitre. De lo contrario, ¿Cómo se entiende una precipitada crisis política de carácter terminal? Tal cual lo plantea Brian Loveman y Elizabeth Lira, el fin del parlamentarismo se dio a "punta de sables" 57 , es decir, con la primera intervención del ejército en el siglo XX que derivó en la remodelación del "Estado en forma". Al respecto, es muy ilustradora la tesis que propone Alain Joxé, cientista político francés, según la cual "las intervenciones de las Fuerzas Armadas aparecen espaciadamente, pero cuando han aparecido, las intervenciones han sido tan importantes y decisivas que llegan a transformar el Estado en profundidad" ${ }^{\prime \prime 8}$.

El resultado de estas contradicciones y transición traumática fue que las expresiones propias de la "cuestión social" sobrevinieron en la más aguda y prolongada crisis social del país durante el siglo XX, cuando no de toda su historia republicana. Este tema ha concitado una cuota importante de atención, tanto es así que desde 1899 empezaron a surgir las primeras reflexiones en calidad de denuncia de la crisis, por lo que la literatura a disposición es más profusa, tanto en la modalidad ensayística, como en investigación histórica.

En consecuencia, es menester señalar ciertas interrogantes que no han podido ser respondidas por la historiografía, o que si han respondido aún dejan preguntas abiertas. Principalmente, ¿Qué ocurrió entre 1880 y 1920, etapa en que el país obtuvo ingresos sin precedentes por exportaciones, y que sólo se igualaron, en términos per cápita, a fines de la década de 1980? ¿De qué carácter era la crisis que estalló en el cambio de siglo? ¿Fue la del proyecto oligárquico o de la sociedad en su totalidad? ¿Cómo se entiende esta incongruencia de acuerdo con la cual la producción historiográfica nacional no ha abordado este tema que cruza el período de la más compleja crisis social -cuando no integral- de este país?

Se puede concluir, provisionalmente, que la "república parlamentaria" es un tema abierto, que requiere de nuevas investigaciones y reflexiones, las que -necesariamentedeben apelar a un enfoque integrador.

\footnotetext{
${ }^{57}$ Loveman, B. y Lira, E., Las suaves cenizas del olvido. Vía chilena de reconciliación política 1814-1932, LOM HistoriaDibam, Santiago, 2000, pp. 283 - 286.

${ }^{58}$ Joxé, A., Las Fuerzas Armadas en el sistema político chileno, Ed. Universitaria, Santiago, 1970, p. 56.
} 


\section{Bibliografía}

\section{Libros}

Ahumada, J., En vez de la miseria, Editorial del Pacífico, Santiago, 1958.

Bauer, A., La sociedad rural chilena. Desde la conquista española a nuestros días, Editorial Andrés Bello, Santiago, 1994.

Burke, P., Venecia y Amsterdam, Estudio sobre las elites del siglo XVII, Crítica, Barcelona, 1996.

Cariola C. y Sunkel, O., Un siglo de historia económica en Chile 1830-1930, Editorial Universitaria, Santiago, 1991.

Carmagnani, M., Estado y Sociedad en América Latina, Ed. Crítica, Barcelona, 1884.

Carmagnani, M., Desarrollo Industrial y Subdesarrollo Económico: el caso chileno, 1860-1920, Dibam, Centro de Investigaciones Barros Arana, Departamento de Ciencias Históricas, Universidad de Chile, Santiago de Chile, 1998.

Castedo, L., Chile: vida y muerte de la republica parlamentaria (de Balmaceda a Alessandri), Editorial Sudamericana, Santiago, 2001.

Collier, S. y Sater, W., A History of Chile, 1808-2002, Cambridge University Press, Cambridge, 2004.

De Ramón, A. Gross, P. y Vial, E., Imagen ambiental de Santiago 1880-1930, Ediciones Universidad Católica de Chile, Santiago, 1984.

De Shazo, P., Trabajadores urbanos y sindicatos en Chile: 1902-1927, Centro de Investigaciones Barros Arana, Santiago, 2007.

Edwards, A., La fronda aristocrática, Editorial Universitaria, Santiago, 1982.

Encina, F., Historia de Chile desde la Prehistoria hasta 1891, Ed. Nascimento, Santiago, 1954.

Heise, J., Historia de Chile. El período parlamentario. 1861-1925, Editorial Andrés Bello, Santiago, 1954.

Hurtado, C., Concentración de población y desarrollo económico. El caso chileno, Universidad de Chile, Santiago, 1966.

Hurtado, C., De Balmaceda a Pinochet, Logos, Santiago, 1988. 
Jobet, J., Ensayo histórico del desarrollo económico-social de Chile, Editorial Universitaria, Santiago, 1955.

Joxé, A., Las Fuerzas Armadas en el sistema político chileno, Editorial Universitaria, Santiago, 1970.

Kirsch, H., Industrial Development in a Traditional Society. The Conflict of Entrepreneurship and Modernization in Chile, University of Florida, Gainesville, 1977.

Loveman, B., Chile: The Legacy of Hispanic capitalism, Oxford University Press, New York, 2001.

Loveman B. y Lira, E., Las suaves cenizas del olvido, Vía chilena de reconciliación política 1814-1932, LOM Historia-Dibam, Santiago, 2000.

Mamalakis, M., The Growth and Structure of the Chilean Economy from Independence to Allende, Yale University Press, New Haven, 1976.

Millar, R., Políticas y teorías monetarias en Chile, Universidad Gabriela Mistral, Santiago, 1994.

O'Brien, T., The Nitrate Industry and Chile's Crucial Transition, 1870-1891, University Press, New York, 1982.

Ortega, L., Chile en ruta al capitalismo. Cambio, euforia y depresión, Dibam-LOM, Santiago, 2005.

Ortiz, F., El movimiento obrero en Chile (1891-1919). Antecedentes, Ediciones LOM, Santiago, 1985.

Salazar, G., Violencia política popular en las "Grandes Alamedas", Santiago de Chile, 1947-1987, Ediciones SUR, Santiago, 1990.

Salazar, G. y Pinto, J., Historia contemporánea de Chile, Ediciones LOM, Santiago, 1999.

Valenzuela, S., Democratización vía reforma. La expansión del sufragio en Chile, Ediciones del Ides, Buenos Aires, 1985.

Vial, G., Historia de Chile, 1891-1973, Editorial Santillana del Pacífico, Santiago, 1981.

Yáñez, J., Estado, consenso y crisis social. El espacio público en Chile, 1900-1920, Ediciones DIBAM, Santiago, 2004. 


\section{Capítulos de libros}

Blakemore, H., "El período parlamentario en la Historia chilena. Algunos enfoques y reflexiones", Dos estudios sobre salitre y política en Chile. 1870-1895. Editorial Departamento de Historia Universidad de Santiago de Chile, Santiago, 1991.

Blakemore, H., "Desde la Guerra del Pacífico hasta 1930", Chile desde la Independencia, Ediciones Universidad Católica Silva Henríquez, Santiago, 2009.

Hobsbawm, E., "De la Historia Social a la Historia de la Sociedad", Sobre la Historia, Crítica, Barcelona, 2008.

Millar, R., "El parlamentarismo chileno y su crisis, 1891-1924", Cambio de régimen político, Ediciones Universidad Católica de Chile, Santiago, 1992.

\section{Artículos}

Burgos, J. y Walker, I., “Hacia el parlamentarismo”, Expansiva, Serie en Foco, 4, 2003.

De Ramón, A. y Gross, P., "Santiago de Chile: características histórico ambientales, 1891-1924", Nueva Historia, 4, 1985.

Fernández, M., “El enclave salitrero y la economía chilena 1880-1914”, Nueva Historia, 1981.

Ortega L. y Araya, P., “Economía política y políticas económicas durante la república salitrera, 1880-1914", Contribuciones Científicas y Tecnológicas, 116, 1997.

Reinsch, P., "Parliamentary Government in Chile", The American Political Science Review, 3 (4), 1909. 